\section{AID OF PHYSICIANS TO CHILDREN AND ADOLESCENTS WHO EXPERIENCED SEXUAL ABUSE}

doi:10.1136/archdischild-2012-302724.0467

R Wolf. Interdisciplinary Department of Social Sciences, Bar-Ilan University, Ramat Gan, Israel

This article discusses children and adolescents who have been the victims of sexual abuse. It focuses on the special role that physicians play in identifying such children and providing them with initial support and assistance. The article discusses the short and long-term effects of childhood sexual abuse, including the physical and emotional impact of sexual exploitation and severe neglect. It presents the effect of this phenomenon on the victims, and how they express and deal with their trauma. It is important for physicians and other medical professionals to be sensitive to the possibility of children being abused, scared, or threatened. It is important to note that if the abusers are members of the child's family, it requires double attention and it's necessary to involve other welfare authorities. In such a case the physician plays a double role - a health provider and supportive figure. The article also includes a discussion of effects that are manifested when the victim has grown to adulthood, such as personality disorders. The method used to treat these abused children is to bring forth loved ones to mitigate the effect of the injury and help the victim deal with the painful feelings it engenders. The purpose of this paper is thus to draw the attention of teachers and school counselors to the importance of identifying these abused children so as to be able to rehabilitate them and allow them to develop properly, as the sexual abuse of children damages not only their present but also their future development.

\section{A REVIEW OF CHILD PROTECTION PRACTICES IN A BUSY DISTRICT GENERAL HOSPITAL}

doi:10.1136/archdischild-2012-302724.0468

${ }^{1} \mathrm{C}$ Walsh, ${ }^{2} \mathrm{~A}$ Livingstone, ${ }^{3} \mathrm{~T}$ Mulroe. ${ }^{1}$ Paediatrics, Altnagelvin Hospital, Derry; ${ }^{2}$ Paediatrics, Antrim Area Hospital, Antrim; ${ }^{3}$ Paediatrics, Enniskillen Hospital, Enniskillen, UK

Background and Aims Following the tragic death of Victoria Climbié in 2003, Lord Laming produced a report setting out a number of recommendations aimed at improving Child Protection (CP) practices throughout the UK. We decided to review our practice in a District General Hospital in Northern Ireland to determine whether recommendations from previous $\mathrm{CP}$ audits were implemented, and in addition check our compliance with the Laming recommendations.

Methods We performed a retrospective chart audit on CP cases presenting to our paediatric department between September 2008 and March 2010. Using recommendations from previous audits and Lord Laming we defined our standards and devised a pro forma for collecting data.

Results Our targets were achieved in a number of areas, in particular medical note keeping, use of CP illustrative templates, documentation of telephone exchanges and face to face discussions, the presence of Nursing Progress Notes, identification of the child's consultant and GP in the medical notes and documentation of results of investigations. We failed to meet our objectives relating to certain aspects of communication, especially taking a history from the child, proper use of interpreters, documenting consent, informing social services in writing and documenting review arrangements.

Conclusions Progress has been made in how we manage these difficult and sensitive child protection cases. However, we have identified a number of areas where we can improve upon our current practice, and have made recommendations that we hope will further aid in safeguarding our children in the future.

\section{EXPLAINING THE UNEXPLAINED: HOW FAR TO INVESTIGATE SYMPTOMS IN LEARNING DISABLED PATIENTS?}

doi:10.1136/archdischild-2012-302724.0469

CL Lea, N Sauven, MPB Thorpe. Department of Paediatrics and Child Health, Royal Cornwall Hospital, Truro, UK

Background and Aims We present a case of a severely autistic 14 year old boy referred to paediatric outpatients with a 1 year history of pica and early morning retching. This was initially considered behavioural in origin. Review of previous Abdominal X-ray (Image 1) revealed a gastric bezoar; at surgery this had resolved but duodenal adhesions were found and divided with recovery of symptoms. Distinguishing which symptoms are behavioural in origin and which are organic can prove a diagnostic conundrum in learning disabled patients. We aim to provide guidance for rational investigation.

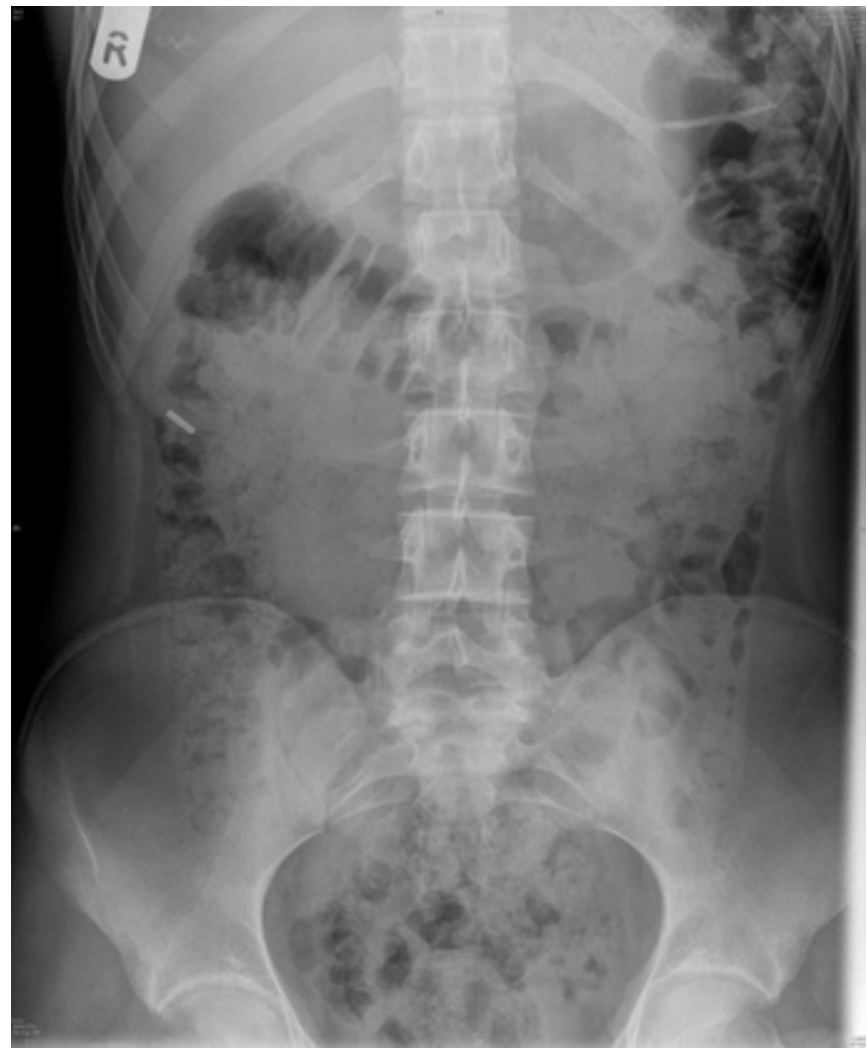

Abstract 469 Figure 1 Gastric Bezoar

Methods We present a literature review on learning disabled children presenting with unexplained symptoms

Results Autistic children have an increased tendency to develop pica, and gastric bezoar causing obstruction is well described. Learning disabled children can also present with a range of gastrointestinal problems including diarrhoea, constipation and vomiting which may also be secondary to pica. Behavioural symptoms may be difficult to distinguish from gastrointestinal symptoms for example gastro-oesophageal reflux.

Conclusions We propose a collaborative approach between general and community paediatricians and present proposed guidance for investigation of symptoms.

\section{0}

BEING INFORMED - A NATIONAL SURVEY ON CONSENT IN UK PICUS

doi:10.1136/archdischild-2012-302724.0470

B Lakin, D Sideras, S Mahoney. PICU, Royal Liverpool Children's NHS Trust, Liverpool, UK 